\title{
Embedded Computing for IoT Using Simple Projects
}

\author{
Luciene Cristina Alves Rinaldi, Adriano dos Santos Viana, Celso Junji Sonehara, Gabriel \\ Pereira da Costa Andrade, Gustavo Souza Azevedo \\ Computer Science, Centro Universitário FEI \\ São Bernardo do Campo, São Paulo
}

\begin{abstract}
The Internet of Things (IoT) allows indoor (home automation) and outdoor electronic objects to communicate through a wireless sensor network and assist controlling and monitoring daily routines through a mobile system. The scenario used in the application was a university campus. Validation of the concept and to verify the correct functioning of the embedded devices, along with mobile application, the indoor environment for the tests was the IoT research laboratory and the outdoor a parking lot.
\end{abstract}

\section{Introduction}

The Internet of Things (IoT) is the new paradigm in the telecommunications scenario. The concept involves crossing information and sensors around intelligent environments, such as sound sensors, actuators, ultrasonic presence detection, infrared, cameras, among others; which are able to interact with one another to attain a common goal through the network using a variety of wireless communications technologies, such as wi-fi, IDentification RadioFrequency (RFID), Global System Mobile (GSM), Near Field Communication (NFC), Bluetooth and ZigBee [10]. These wireless sensor networks are used for monitoring, tracking, processing and coordinating tasks, cooperating with each other [1] in the execution of certain actions using one type of actuator [2].

Other definitions also used as synonyms are connected environments, ubiquitous computing, mobile computing, embedded computing, web of things, internet of the future and intelligent cities [1] [7] [8]. IoT began to gain importance in the second half of the year 2000 and it was also related to intelligent environments, e.g. houses, cities, cars, radio frequency tags, geolocation, privacy problems, parking lots, meeting rooms, research laboratories, among others.

In this scenario, the tasks of monitoring intelligent environments were inserted in different and complex applications and using solutions based on the automation of this type of environment became an interesting challenge for the conduction of the researches in our laboratory.

The need for intelligent objects with capacity for sensing, processing and communication has increased in recent years. IoT brings great possibilities for the development of the use of hardware for these environments, in other words, embedded devices (e.g. using arduino or raspberry). An embedded device is built to perform specific tasks and continuously interact with the environment through sensors and actuators. These systems are usually designed to be independent from a fixed power source such as a wall socket. Their main features are computational capacity, reduced size, cost, reliability, performance and its autonomous independence. Some of them are mass-produced, benefiting from economies of scale, e.g. mobile phones, automobiles, microwave ovens, digital clocks, traffic lights, sonars, modems, complex systems, among others [6] [12] [16] [17].

The term IoT indicates situations where the computational capacity allied with modern networks extends to embedded devices (objects) and everyday items (e.g. home appliances) with the capacity to generate exchange or consume data with less human intervention [13]. IoT devices are increasingly present in our lives and the benefits provided begin to transform everything that is known from business and government to homes and hospitals around the world [14].

This article presents some prototypes that can be easily reproduced by beginners in the area and have been implemented in our University to bring environmental and economic benefits to the automation of environments, helping in the security and reduction of costs for the institution. Besides, it is known that electric energy is a fundamental resource and its use in a sustainable way is paramount for the environment and for future generations.

The objective of this paper is to present the study of IoT applications, and the scenarios are presented in sections III, IV, V and VI. An IoT architecture was proposed for different scenarios and applications in section II, through hardware and software suitable for each of these environments. Finally, the final considerations are presented in section VII.

\section{Project Architecture}

The IoT allows a set of physical objects and applications in software and hardware that communicate anywhere and anytime connecting the real world with the digital world [1] [5]. Through the integration of several technologies, IoT has made possible to reduce the size, weight, power 
consumption, price of embedded devices, with wireless technology and communication capability [9].

When thinking about building mobile applications, it is necessary to decide the platform that will be used, such as Android, iOS, Windows Phone, BlackBerry, Tizen, among others. Android dominates most smartphones, especially in Brazil, followed by iOS which is widely used.

One of the big problems is writing native applications that serve all platforms since each platform has its language combination and specific APIs (which change frequently).

When talking about web programming, this problem does not exist because the pages are standardized, and these scenarios use the same type of code, i.e. they are standardized languages like HTML, CSS, JavaScript and Node JS with APIs that work everywhere. However, these languages are not installable the same way the Apps, as they do not integrate with the advanced resources of the mobile equipment (smartphones and tablets).

Therefore, the multiplatform Cordova (currently modified for PhoneGap) was used in the construction of the applications. This platform uses the web's strong points of having standardized languages, the web browser and the ability to build hybrid installable applications of the chosen platform, but which have been written in HTML, CSS and JavaScript [11].

The choice of using a hybrid application is the lowest development cost and a single code that serves all platforms. It will not need to have specific teams for programming in Java and Android for maintenance. This is the main argument for choosing the language, as well as database, server, and others. Another justification is that students already have knowledge of HTML, CSS, JavaScript and JS (discipline taught in the first semester of the Computer Science course) and the learning curve for the hybrid application is quite small.

A virtual server was created in computer using the VMware software with the Ubuntu operating system. The server was programmed in Node JS and the database installed was MongoDB. Data communication with the applications was done using the ESP8266 wi-fi module.

The architecture of the project was divided into four parts and organized into four layers, as we can see in Figure 1.

Linux kernel: it is the kernel on which the project was based. This layer has all the low-level drivers of hardware components, such as wi-fi, ultrasonic, infrared, among others.

Libraries: they contain all codes that provide the main supports for the applications, e.g. the database.

Application Framework: it exposes various operating system resources for developers to use in programming.
The main modules of the mobile application are: module with business rules, wi-fi module, module of notifications and the module that performs communication as a backend using webservices.

In the backend part, we can find the web part of the solution together with the communication webservices used by the mobile communication and the database (see Figure 2 of the application structure).

The Figure 3 shows the Use Case Diagram (DCU) in Unified Modeling Language (UML) as example of one the applications.

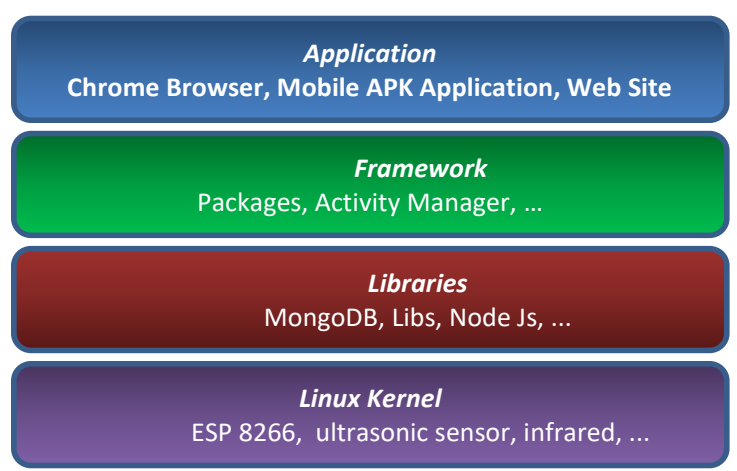

Figure 1. Project Architecture

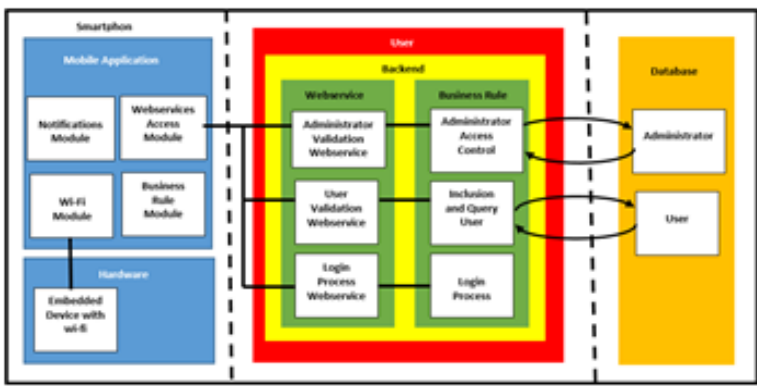

Figure 2. Example of structure of one application

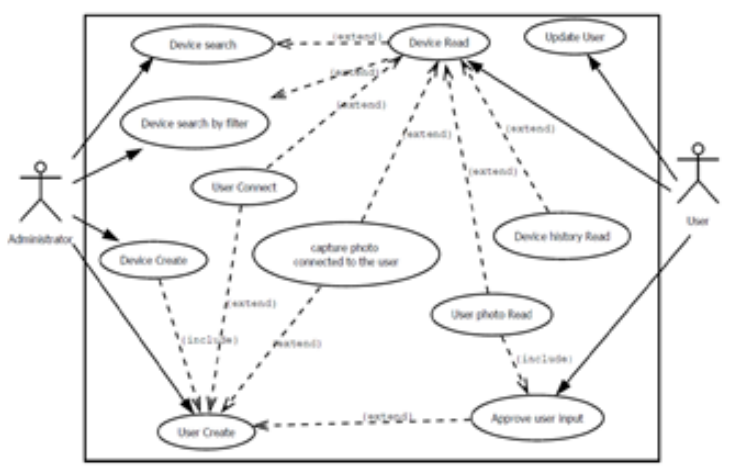

Figure 3. Example Use Case Diagram (DCU) in Unified Modeling Language (UML).

\section{Embedded Mobile System For Access Control}

Here is presented an embedded solution for controlling access and monitoring real-time 
environments, such as houses, offices, shopping malls, condominiums, classrooms (elimination of the attendance sheet), parking lots, libraries, factories, laboratories (student profile control) or any other environment that needs access control.

A multiplatform mobile application and website were created via wi-fi network with the ESP 8266 component for sharing information on the network that assists in controlling and monitoring the environment for the reduction of financial and human resources costs (regarding working hours, human errors and employee`s or teacher's complaints) and security (such as replacing the traditional attendance sheet) by automating the activities of the IoT research laboratory. [15] developed a context-based intelligent access control framework focusing on smart homes with contextual user data, like location, profile, calendar, access time, and behavior patterns similar to what was used in the laboratory.

The project demonstrated examples of the study and comparison of some sensors (RFID sensor, GPS for monitoring the student's position using the mobile phone, biometric sensor, QR-Code, face recognition camera, among others) with an Arduino Mega device. A possible problem is that a student can pass the RFID card on an embedded device installed at the entrance of the classroom pretending to be another student without him or her being in the university. Therefore, a "double-check system" with a combination of RFID, biometric recognition and a keyboard for password coding was initially analyzed. Then, a fusion of sensors was tested in real time like other solutions, e.g. the camera for facial recognition.

Figure 4 and Figure 5 shows the electric scheme and construction of the initial prototype. Wireless communication was used to transfer sensor information to the server that can be monitored through a cross-platform web application using tablets and smartphones. This information can also be transmitted across the network and be used for cross-information, such as classes, subjects, schedules and classrooms.

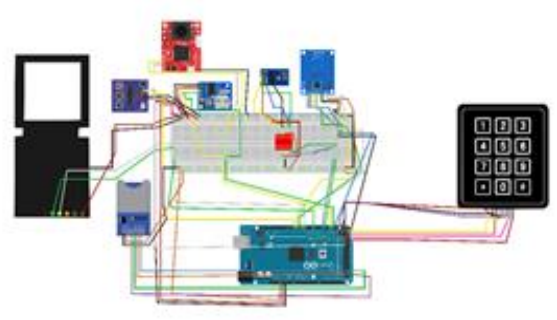

Figure 4. Electrical schematic of the initial access control prototype

The same system can be used to monitor incoming data for students at the university, should this be necessary in the future. You can use the same card used in the library to enter in the university, also using turnstiles for the entrance or exit from the campus or just GPS from the student's smartphone. With this and knowing when students enter or leave the university, we would also have information of when they are in the classroom and crossing the information, one can compare how long they have been in the classroom $\mathrm{N}$, how long have not been in classroom $\mathrm{N}$ and the length of time they are in college. When it is known that $\mathrm{X}$ students are in class, in the $\mathrm{Y}$ rooms in building $\mathrm{K}$, the facilities area will have information, for example, to predict from the data, when to clean and supply (with relevant products) the toilets.

The monitoring of information allows us to build big data for analysis and prediction based on student behavior on campus. All information in the application is monitored and can be modified in real time on the web (it can be accessed through the browser of computers, notebooks or smartphones of any operating system) by authorized employees.

The big challenge was to be able to solve the problems of environment automation by combining hardware with low cost and low processing power (aiming at the energy efficiency of the system itself) and achieve a good performance. Some similar works are presented below.

The work [19] considered the obstacles to the propagation RFID signals. The same considerations of occurrence were tested for the presence of people. The approach in [20] used bar code and Raspberry Pi to control people in restricted areas using the web.

The system created by [21] performs the authentication using human face biometrics for the control of access to restricted areas, with the hardware in simple embedded devices. The [22] carried out the access control analysis with the capture of the image of the palm and its digitalization, allied to the technique of Artificial Neural Networks. The results obtained from this technique for the studied cases were extremely satisfactory.

The autors [23] proposed an intelligent lock with the facial detection of the user. The smartphone application starts with communication through an Arduino Bluetooth module to authorize access. [24] have created a system that uses Bluetooth low energy, aiming the accessibility of people who somehow can not open a door using conventional means. The work cited the use of embedded components similar to those used in this project.

The autors [25] utilized the Near Field Communication (NFC) to demonstrate two application cases. One of them uses the LLCPS protocol, which is a kind of Transport Layer Security (TLS) protocol that runs within the Logical Link Control Protocol (LLCP) and allows P2P (Peer-toPeer) communication between NFC devices. In this 
case study, the key is stored inside the cell and transmitted to the lock. In the second case study, the key is remotely allocated and passed to the system using the EMV protocol (this protocol is the same used for the recognition of chips present in credit cards).

The autors [26] have developed a context-based access control framework focused on smart homes with such contextual user data such as location, profile, calendar, access time, and user behavior patterns upon access. It is possible to create a smarter form of access, not only for smart homes, but also for other environments where greater security is needed.

The work [27] has used the IR sensor technology present on some models of arduino and raspberry-pi prototype platforms to create a smart lock. Another [28] have created an RSA (Rivest Shamir Adleman) algorithm for data encryption with the use of gestures. In this system, a mobile phone is connected to a development board in the receiving terminal via Bluetooth and after the gesture password has been entered, users can load the door lock / unlock information on the server in the cloud via $\mathrm{Wi}-\mathrm{Fi}$, without having to use a personal computer.

The project [29] used wireless technology to monitor and control a residential door at a distance using an android application. The system not only informed in real time the unauthorized opening of the door but also warned the neighbors that the house next door was violated. This system also used cloud computing to perform the data coding and enable the addition of authorized persons to enter the residence through the mobile interface.

Another project [30] proposed a blockchainbased smart lock where each of the people who have access to the environment in question would be a node in the blockchain, ensuring the integrity of the entire system.

The autors [31] proposed a system that uses several cryptographies and RFID focused on critical areas. This system can authenticate, validate and unlock the door to the user in real time. It can also use an android application with OTP technology that guarantees this system a layer of security beyond the encryption involved.

\section{Embedded Mobile System For Intelligent Enviroment Lighting}

This was aimed to automate and monitor the lighting of intelligent environments (similar to the applications of smart houses) through an embedded device using IoT. These environments can be homes, offices, classrooms, meeting rooms, parking lots, libraries, laboratories, among others, using IoT sensors to save electricity.

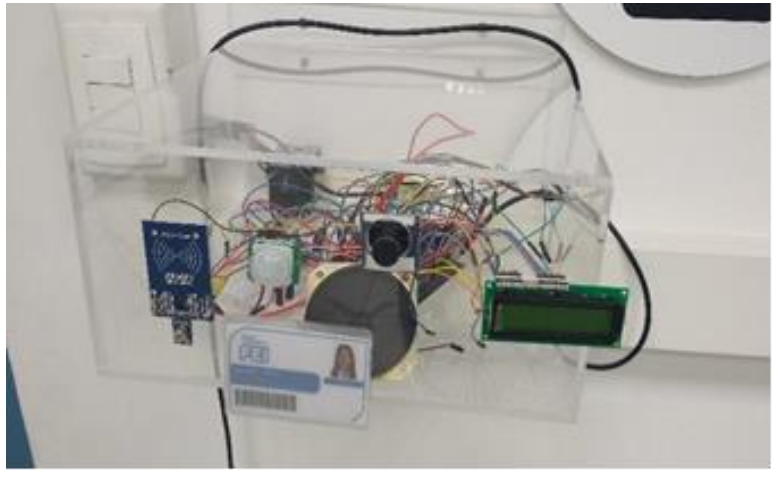

Figure 5. Initial access control prototype

The device is focused in avoiding unnecessary expenses with electricity. A multiplatform mobile application and a web site were built to assist in the collection of data for the monitoring of information. This project specifically aims the automation and monitoring of the environments helping to reduce the financial and human resources of the institution and the IoT laboratory (Figure 5). As such, building inspectors can monitor with a tablet or website by viewing the maps of all classrooms per floor.

The RFID sensors were used to detect users' input through the library card (which has its identification and a tag that responds to the RFIF, or a key chain with the tag) to control the number of people entering and leaving the environment.

Another solution thought out was the PIR-based motion detector, but as most people already use it in their condominiums, it does not work as expected because when there is no movement with a certain time limit, it goes off even when there are no people around.

A fusion of sensors was tested with the infrared body heat sensor combined with the PIR-based motion detector. These are some of the initial ideas before putting the set to work with the wi-fi sensor so that this device works on the network to "talk" with other devices in the environment. Then, the software was built to control this embedded device via website, mobile phone or tablet.

We adopted a strategy of phased deliveries, according to the need and the identification of optimization of tasks to be used, developing the hardware and the software throughout this work. The building inspectors currently delivers a little bag to the teachers containing the specific classroom key, pens for whiteboard and remote control for the datashow projector. Only one RFID device was placed at the building inspectors' desk (Block K's first floor, security cabin) and a key holder (tag) on each classroom bag that teachers receive. In these tags, all the necessary information is registered, such as classroom number, teachers who use them, time of entrance and time of exit. With this, it is possible to control the lighting of the rooms because when the 
inspectors pass the key on the embedded device with the RFID sensor, the lights are turned on/off.

Additionally, a report of rooms, timetables, teachers, entrance and exit, as used by the inspectors on a day-to-day basis, can be printed at the end of every day by the inspectors. The next step is to present all the rooms on the floors of Building $\mathrm{K}$ (pilot project) where inspectors can monitor as "a live map where they can choose the numbered floor", i.e. choose any room, check if the lighting is correct or not, if the air conditioner is on/off, if the projector is on (if the teacher forgot to turn it off), and through the tablet solve these issues whenever the inspector is in the building or on the website.

As for climate control, a temperature sensor can measure room temperature constantly and by using wireless communication, it can transfer sensor information to the server. Software programmed to maintain the set temperature controls the "on/off" feature in the same way light is controlled. This software may have access to information such as classes, subjects, or activities programmed for that room. If no student/teacher enters, information obtained through the motion sensors, RFID or infrared (not yet defined) will automatically turn off the light, air conditioner or projector.

A brightness sensor can also be used which will transmit information through the network to the server to cross information regarding classes, disciplines, time and rooms at night, for example.

The air conditioner and projector follow the same rules. In this case, they will only be implemented in the laboratory, as the air conditioning of Building $\mathrm{K}$ is currently controlled in another way. The same system can be used to monitor input data from students at the university, should this be considered in the future.

The same student's library card may be used to enter the university going through the turnstiles (or by GPS) for students to enter/exit the campus. With this, knowing when the students enter/leave the university, we would also have information on how many students are in class in $\mathrm{Y}$ rooms of Building $\mathrm{K}$ versus other buildings. Crossing this information, it is possible to be compared, for example, in the night period, concentrating in one part of the campus, deactivating (or dimming) the electrical power in other parts, reducing the student-building-car route on rainy days. It is possible to dim the lights (if they have this feature) in night-time scenarios and with less student traffic in certain regions of the campus by using Arduino's PWM digital pins along with the RTC to determine the period of time in which this action will occur. With this monitoring information, it will allow us to build a big data for analysis and forecasting based on student and campus behavior. All information in the application can be monitored and modified in real time on a tablet, mobile or the web (accessed by the browser or notebooks) by the inspectors, who need to be registered and given permissions to make modifications or alter the settings. The system contains the log for auditing and compliance. Some similar works are presented below.

The work [32] presented an energy efficient system with the use or complementation of natural light, in addition to automatic lighting controls. The theoretical computer simulation models used several sensors to capture the intensity of light and presence to regulate the amount of light through 3 lighting models and 3 types of windows, totaling 63 different models and calculating the PALN (Percentage of Utilization of Natural Light) of each of them.

The work [33] of the University Center of Brasilia (UNICEUB) involved an intelligent circuit connected to the computer to control individual areas of a given environment. The objective of the work was to propose a form of control of the lighting that integrates and interacts with the manager and all the points of luminosity of the environment. It used a hardware available in the popular markets, in homes and companies with Arduino platform (Atmel microcontroller Atmega328), connected by the USB port to the switching center, that has an interface to execute the commands in the "PHP" programming language.

The autors [34] have developed a home automation system via TV remote control or air conditioning. Regular 220VAC lamps and 5VDC relays were used. For the implementation of the code in the Atmel microcontroller in the Arduino, the Arduino IDE version 1.0.07 was used. To perform the communication between the Arduino and remote control was used an infrared receiver that functions as an IR filter. The demodulated output signal can be directly decoded by the microprocessor.

Another autors [35] proposed a computational architecture that allows the implementation of intelligent environments in cooperation with the automation company Homesystems. The work focuses on intelligent temperature and light control based on sensors and schedules to optimize energy consumption and thermal comfort using Personal Digital Assistants (PDAs) to remotely control the environment and multimodal interface for a more natural user interaction with the environment. In the implementation was used different modules designed by Homesystems, connected in a network, being able to function both dependent and independent of a central controller module called Systembox where communication occurs between sensors and the activation of actuators (lamps, etc.). In multimodal interaction the user can use modules for keyboard and handheld devices.

The project [36] used a Programmable Logic Controller (PLC) with a rain sensor to open / close the window, turn on/off the motor that collects a clothesline, two presence sensors to control the 
entry/exit of people, one at external side and one in the inner side. When a certain order of activation of the sensors occurs, it is known that someone has entered or left the environment and thus can control the light. The PLC receives data from the sensors and activates the motor, lights or other sensors.

Another project [37] presented a system for monitoring soil moisture, light intensity, air humidity and ambient temperature to maintain higher productivity in a greenhouse and reduce waste. The system used RFID, camera and motion sensor to observe unauthorized entries, and could be deactivated remotely by a web interface.

The work [38] implemented a prototype of a selfsustaining smart-house using solar panels, heat sensors, movement, current and a battery. The application saves system data as well as monitoring energy costs such as the lights on and room temperature using arduous scattered around the house and sending information over wi-fi through the monitoring sensors of each room. In [39] were used temperature, fire and smoke sensors. In this project, an alert message and an email are sent to the home owner if a problem is found. It also has a heat sensor, light and a motor to control shutters automatically depending on the light and ambient temperature, plus the motion sensors to turn on/off lights and fans.

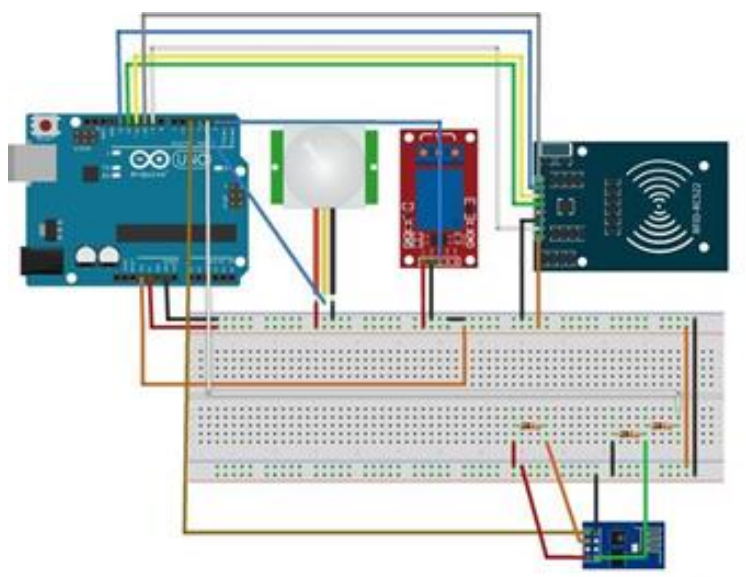

Figure 6. Initial system for intelligent environment lighting prototype

\section{Embedded Mobile System For Smart City Monitoring}

This work is in accordance with the Smart City theme from the perspective of being related to the external physical environment in which communication and information technologies, as well as sensors and physical objects, disappear as they are embedded in the environment in which we live and work. Therefore, it presents a solution that aims at the dynamic control and monitoring for parking lots of companies, condominiums, universities, malls, etc. Figure 7 presents the prototype through a mockup and Figure 8 shows the electrical schematic of the initial prototype.

Ultrasonic sensors were used which are placed on the wall in front of the vehicles to control the proximity and warn by identifying a light of an RGB led if the garage is occupied (red) or free (green) for the user. The spot for disabled people are represented by a blue led. A display at the parking lot entrance shows the number of occupied / free garages on the property for users to know before entering the parking lot (or in each spot, for example). Depending on the size of the lot, several displays can be installed per hallway. At the entrance / exit of the parking lot, the gate is opened using step sensors, together with ultrasonic sensors to detect the distance of the vehicles according to the proximity to the opening of the gate automatically. Another step sensor was used along with a camera to capture the images and make the administrative monitoring move automatically, as most condominiums and malls already do, aiming at the safety of the environment. Viewing the images is intended only for remote site monitoring, i.e. it is only a video transmission. The treatment of camera images is not the focus of this work. An ESP8266 wi-fi module was used for wireless communication to transfer information from the sensors to the server, which can be monitored via the web and the cross-platform application, using a tablet, notebook, computer or smartphone, making it easier for administrators to access information, such as the number of registered users, daily, weekly, or monthly flow, etc., in addition to per-camera monitoring.

One of the main functions of the application, in the case of a company or even a condominium, is that tenants can rent their parking space (sharing of vacancies) that can help many individuals depending on where they live, for example in the center of São Paulo, where the client can enter the application on the site or smartphone and rent the parking space in advance. The information is transferred to a QRCode facilitating the control of the flow of activities. When the customer arrives in the condominium and passes his or her cell phone in the application or device shipped at the gate of the condominium, the QR-Code containing the vehicle's data, payment and data of the client is verified. If everything is $\mathrm{OK}$, the client is allowed entrance. The same system works for a company, university or private parking lot. Some similar works are presented below.

The work [40] aims to build a system less dependent on the human being, through the automation of the cars, as well as of all the parking, removing the need for the owner to park his vehicle. Automation in the car is achieved through Path Tracing (computational method to render images of three-dimensional scenes so that global illumination is true) using IoT sensors. 
Another work [41] introduced a cloud-based intelligent parking system for use on a university campus using a number of software solutions including Kafka, Storm, Hbase clusters, OSGi web applications with distributed NoSQL, with a rules engine and mobile applications proposed to provide better parking service experience for users. A detailed specification of the location of the position is given, indicating the direction ("right", "left") to the driver of the vehicle until it finds it.

Another paper talks about a prototype developed using the RFID sensor based on IoT. The RFID sensor is used to detect the details of the car, and the IR sensor (Infrared Sensor) is used to find the presence of the car and all details are accessed remotely. This system helps the user to find availability of parking space with the help of IoT technology providing information of which vacancies are free. Drivers can book slots in advance and parking information is updated on the server. In addition, theft management is done by checking the license plate in a database [42].

In the publication [43] the system has in its operating principle a matrix computing model. The project uses the Arduino open source platform to locate and account for available vacancies using ultrasonic and LDR sensors that detect the presence of the vehicle. Then, through a communication system, the vacancies share the same connection and each one is identified by means of a binary number, and the microcontroller is responsible for sending to the displays the locations with trajectory of the vehicles, the total number of vacancies for general public as well as the elderly and people with special needs.

The project [44] presented a new algorithm that increases the efficiency of the cloud-based intelligent parking system and develops a network architecture based on IoT technology. This study aimed to provide information on nearby parking places. In this system the driver can make a reservation a few minutes before arriving using a device like smartphones or tablets. RFID cards are used to identify users. The application sends the information to a cloud server and users access the system over $3 \mathrm{G} / 4 \mathrm{G}$ connections.

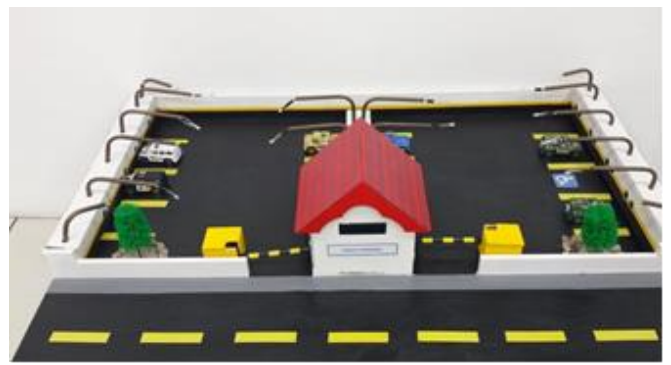

Figure 7. Presentation of the prototype through a mockup

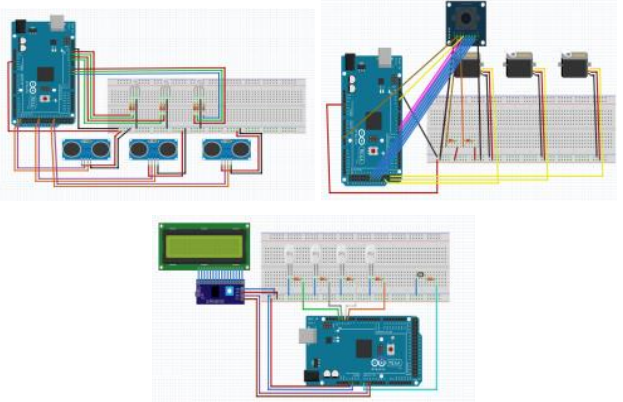

Figure 8. Electrical schematic of the initial prototype

\section{Using Automation To Build A Mobile System Aimed To Improving Daily Routines}

This work goes within the automation theme from the perspective of being related to devices to automate the routines and tasks of a house, simplifying the daily life of the people and satisfying their needs of communication, comfort and security. Thus, the concept was demonstrated by presenting solutions of IoT as the automation of the control of a simple electric coffee maker according to the rules of the environment where it is inserted to reduce the electrical energy, as well as the control and monitoring of the air conditioning and a TV. This has brought environmental and economic benefits, as it aimed at automating the environment, helping to reduce financial resources through the reduction of electricity consumption. In addition, IoT sensors were used to monitor the environment through the construction of a multiplatform mobile application and a website on a wi-fi network. The user can access the application on the smartphone while at work and leave their home electronic devices, for example, scheduled (or programmed) to perform activities when they arrive at home after work.

In the laboratory of the University, such device was used with the purpose of turning on and off the electronic equipment according to the input/output of the students or teachers. It has an ultrasonic sensor to detect the presence of people, an RTC (to check the time to turn on and off equipment such as the coffee maker, air conditioning and TV) (see Figure 9 and Figure 10), a relay (to switch on/off the controlled appliance), infrared sensors to control the access to the TV and air conditioning and a display (to show the output information, such as the last coffee pot that was produced and informing the appropriate time for consumption).

The ESP8266 component was used to wirelessly communicate with the Internet to transfer information from the sensors to the server so that it can be monitored through the cross-platform and web application.

One of the first tests with the prototype was carried out with the mobile device through twitter, as in the Paiman project [18]. The water, the filter and the coffee powder were placed in the simple coffee- 
maker (appliance) and on another day when one of the students from the IoT lab left home for the university, he sent a message via twitter giving a command to the coffee maker to power on the coffee machine connected to the Internet. When he arrived at the IoT's lab, the coffee was ready. Some similar works are presented below.

In the project [45], the monitoring system checks whether the coffee maker is on/off, as well as the coffee temperature and the water level of the carafe in the coffee maker. Users receive these values on their cell phones simultaneously and do the remote control to save energy. The system can lock or unplug the switch automatically.

The work [46] presented a method of temperature control of an intelligent coffee machine based on PIC16F877A (a MCU from Microchip Technology Inc). This solution can maintain the temperature at a precisely adjusted value due to self-adjusting of the liquid level of the coffee. The control system proved to be stable and advanced.

The project [48] uses a chamber for water supply and coffee flow monitoring, a pump and a continuous flow heater to heat the water. The heater has low heat capacity and therefore can perform large temperature changes within a short time. A control circuit was used to obtain the water start-up temperature [47].

The project [49] aimed to provide a cheaper and affordable way to purchase an espresso machine. It used a temperature controller similar to a PID, consisting of an Arduino Uno, nanoshield thermocouple max31855, temperature sensor type K, solid state relay (SSR), plus an OLED display with I2C.

The work [50] introduced a device called the Arduino Coffee Pot. This coffee maker allows the user to start the coffee machine from anywhere with a twitter message from a smartphone connected to the internet through an Arduino. The objective of the project was to connect household appliances to the social network using a System Development Lifecycle (SDLC) methodology, that is, a standard process followed in an organization to perform the necessary steps for analysis, design, implementation and maintenance of a system of information.

The project [51] presented a device with speech recognition system for the disabled that can be used offline. The interface was developed using a speech recognition module and for communication between the modules an ESP8266. The android application [52] also uses voice commands to control and monitor the devices of a home automation network for the disabled. The project [53] allows the control of smart objects through the mobile device based on the touch screen.

The work [54] has developed a system architecture consisting of hardware and software components for remote control of temperature parameters from a domestic environment to increase energy efficiency.

Another work [55] presented a home automation system wi-fi that allows the control of devices in a domestic environment using a cell phone with bluetooth. The cell phone communicates with the main module (bluetooth / zigbee) and other secondary modules, acting as coordinator of the network where the electrical devices are connected.

The project [56] have created the House+ Project (a smart house focused on people with down syndrome) that uses a wireless sensor network (WSN) with heterogeneous devices to monitor the environment through indication signs, messages and alarms (in case of incorrect actions).

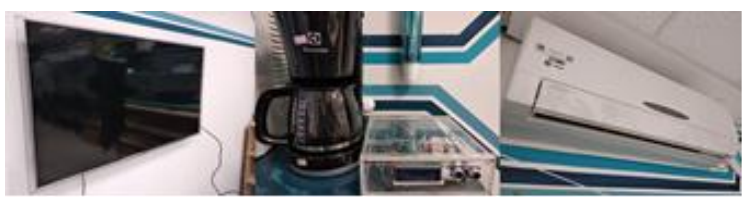

Figure 9. Coffee maker, air conditioning and TV in the initial prototype

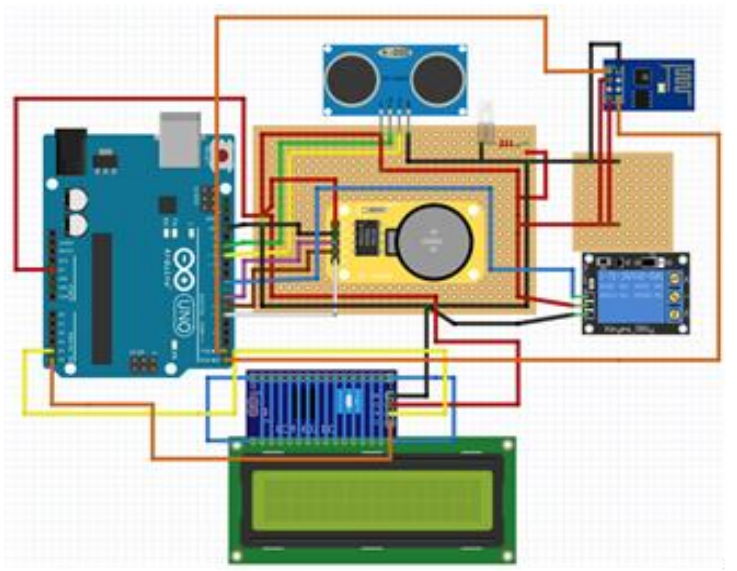

Figure 10. Electrical schematic of the initial prototype

\section{Final Considerations}

This article presented a study of IoT applications in an academic environment with four examples of embedded devices controlled by mobile software. An architecture was applied in some scenarios such as classroom, research laboratory and parking lots. Simulations with the wi-fi network among connected applications were made to verify and validate the correct operation of the proposed applications. The new IoT technologies can bring benefits to control and monitor environments, security (protection of the environment with access control) and reduce costs, such as physical (energy) and human resources (substitution of the attendance sheet in the classroom, which demands much labor). 


\section{References}

[1] Atzori, L. I.; I., Antonio; M., Giacomo. The internet of things: A survey. Computer networks, v. 54, n. 15, p. 2787-2805, 2010.

[2] Akyildiz I. F.; Kasimoglu, I. H. Wireless sensor and actor networks: research challenges. Ad Hoc Networks, 2, 351-367. 2010.

[3] Akyildiz, I. F.; W. Su; Y. Sankarasubramaniam; E., Cayirci. A survey on sensor network, IEEE Communications Magazine, 40(8), 102-114. 2002.

[4] Lee, Valentino; SCHNEIDER, Heather; SCHELL, Robbie. Aplicações Móveis - Arquitetura, Projeto e Desenvolvimento. Editora Pearson Makron Books. 2006.

[5] Miorandi, D.; Sicari, S.; Pellegrini, F.; Chlamtac, I. Internet of Things: Vision, applications and research challenges, Ad Hoc Networks 10: 1497-1516. 2012.

[6] Chase, O.; Almeisa, F. J. Sistemas embarcados. Mídia Eletrônica. Available in: www.sbajovem. org/chase. Access in: 10/01/2018. v. 10, n. 11, 2007.Heath, 2003.

[7] Kranenburg, R.; Anzelmo, E.; Bassil, A.; et. al. The Internet of Things. 1st Berlin Symposium on the Internet and Society. 2011.

[8] Uckelmann, D; Harrison, M.; Michahelles, F. (Orgs). Architecting the Internet of Things. Springer: Nova Iorque, Dordrecht, Heidelberg, Londres, 2011.

[9] Weinstein, R. RfId: a technical overview and its application to the enterprise. It Professional, 7(3), 2733. 2005

[10] Lee, C. T.; Chung, T. C. Shen and K. W. Weng, Development of electronic locks using gesture password of smartphone base on RSA algorithm. International Conference on Applied System Innovation (ICASI), Sapporo, pp. 449-452. 2017.

[11] Lopes, S. Aplicações mobile híbridas com Cordova e PhoneGap. Casa do Código. 192p. 2016.

[12] Cunha, Alessandro F. O que são sistemas embarcados. Saber Eletrônica, v. 43, n. 414, p. 1-6, 2007.

[13] Singh, S.; Kaushik, A; Chitkara, S. S. Ubiquitously controlled personalized smartlock. 2017 International Conference on I-SMAC (IoT in Social, Mobile, Analytics and Cloud) (I-SMAC), Palladam, pp. 686691.2017

[14] Ye, Y. M.; Jiang, N.; Yang, H; Yan,Q. Security analysis of Internet-of-Things: A case study of august smart lock. 2017 IEEE Conference on Computer Communications Workshops (INFOCOM WKSHPS), Atlanta, GA, pp. 499-504. 2017.

[15] Ashibani, Y.; Kauling, D; Mahmoud, Q. H. A context-aware authentication framework for smart homes. 2017 IEEE 30th Canadian Conference on Electrical and Computer Engineering (CCECE), Windsor, ON, pp. 1-5. 2017.

[16] Heath, Steve. Embedded systems design. EDN series for design engineers (2 ed.). Newnes. p. 2. 2003.

[17] Jabeen, Qamar, et al. A Survey: Embedded Systems Supporting By Different Operating Systems. (2016).

[18] Palman, S. Murni. Arduino Coffee Pot Via Twitter. (2013). Available in: http://eprints.utem.edu.my/13870. Access in: 21/ 08/ 2017.

[19] Barros, Daniel Braga et al. Taxa de ocupação em função da variação de potência de sinal recebido em redes de sensores sem fio. In: VIII Workshop de PósGraduação e Pesquisa do Centro Paula Souza. 2013.

[20] Stumpf, N. Fabianna; Cittolin, Guilherme Francescon; Souza, Vinicius de. Desenvolvimento de um sistema web de controle de acesso. 2015. Trabalho de Conclusão de Curso. Universidade Tecnológica Federal do Paraná.

[21] MORAES, J. L. Controle de Acesso Baseado em Biometria Facial. 2010. Dissertação de Mestrado. Universidade Federal do Espírito Santo.

[22] FONTANA, Danilo Rodrigues; MARIM, L. Sistema de Autenticacão/Identificação pessoal biométrica através da palma da mão com o auxílio de redes neurais artificiais. Anais do 140 Encontro de Iniciação Científica e Pós-Graduação do ITA-XV ENCITA, SP, Brasil, 2009.

[23] Gusmão, Arthur Trindade A.; Castro, Agostinho L. S.; Zampolo, F. Ronaldo. Fechadura Baseada em Reconhecimento Facial via Dispositivos Moveis Android. Anais do XXXIV Simpósio Brasileiro de Telecomunicações, 2016.

[24] Prakash, Y. W.; Biradar, V.; Vincent, S.; Martin, M.; Jadhav, A. "Smart bluetooth low energy security system," 2017 International Conference on Wireless Communications, Signal Processing and Networking (WiSPNET), Chennai, India, 2017, pp. 2141-2146.

[25] Urien, P. "A secure cloud of electronic keys for NFC locks securely controlled by NFC smartphones," 2014 IEEE 11th Consumer Communications and Networking Conference (CCNC), Las Vegas, NV, 2014, pp. 1120-1121.

[26] Y. Ashibani, D. Kauling and Q. H. Mahmoud, "A context-aware authentication framework for smart homes," 2017 IEEE 30th Canadian Conference on Electrical and Computer Engineering (CCECE), Windsor, ON, 2017, pp. 1-5.

[27] Dhondge, K.; Ayinala, K.; Choi, B. Y.; Song, S. "Infrared Optical Wireless Communication for Smart Door Locks Using Smartphones," 2016 12th International Conference on Mobile Ad-Hoc and Sensor Networks (MSN), Hefei, 2016, pp. 251-257. 
[28] Lee, C. T.; Chung, Y. C.; Shen, T. C.; Weng, K. W. "Development of electronic locks using gesture password of smartphone base on RSA algorithm," 2017 International Conference on Applied System Innovation (ICASI), Sapporo, 2017, pp. 449-452.

[29] Singh, S.; Kaushik, A.; Chitkara, S. S. "Ubiquitously controlled personalized smartlock," 2017 International Conference on I-SMAC (IoT in Social, Mobile, Analytics and Cloud) (I-SMAC), Palladam, 2017, pp. 686-691.

[30] Han, D.; Kim, H.; Jang, J. "Blockchain based smart door lock system," 2017 International Conference on Information and Communication Technology Convergence (ICTC), Jeju, 2017, pp. 1165-1167.

[31] Mathew, M.; Divya, R. S. "Super secure door lock system for critical zones," 2017 International Conference on Networks \& Advances in Computational Technologies (NetACT), Thiruvanthapuram, 2017, pp. 242-245.

[32] SOUZA, Marcos Barros de et al. Potencialidade de aproveitamento da luz natural através da utilização de sistemas automáticos de controle para economia de energia elétrica. 2003.

[33] ALMEIDA, Gustavo Caetano de. Sistema controlador de iluminação de ambientes através de interface computadorizada. 2010.

[34] SILVA, Daniel Patrício da. Sistema de iluminação com Controle Remoto.

[35] PEROZZO, Reiner Franthesco; PEREIRA, Carlos Eduardo. Ambientes Inteligentes: Uma arquitetura para cenários de automação predial/residencial baseada em experiências. III Encontro de Tecnologia de Informação e Comunicação na Construção Civil, Porto Alegre, 2007.

[36] BRAGGION, Diogo. Automação Residencial: Implementacão de tarefas automatizadas residenciais. Itatiba, 2008. Trabalho de Conclusão de Curso, Universidade São Francisco, Itatiba, 2008.

[37] Ram, S.; Siddarth, N.; Manjula, N.; Rogan, K.; Srinivasan, K. Aravindhu. Real-time automation system using Arduino; International Conference on Innovations in Information, Embedded and Communication Systems (ICIIECS), 2017.

[38] Muhammad Akmal; Arwa El Kashif; Mohammed Ghazal. Demand response enabled sustainable smart home design in the middle east environment Anas $\mathrm{Al}$ Tarabsheh 2016 IEEE 16th International Conference on Environment and Electrical Engineering (EEEIC), 2016.

[39] Riyaj Kazi; Gaurav Tiwari. IoT based Interactive Industrial Home wireless system, Energymanagement system and embedded data acquisition system to display on web page using GPRS, SMS \& E-mail alert. International Conference on Energy Systems and Applications, 2015.

[40] BONDE, D. J. et al. Automated car parking system commanded by Android application. In: Computer
Communication and Informatics (ICCCI), 2014 International Conference on. IEEE, 2014. p. 1-4.

[41] JI, Zhanlin. A cloud-based car parking middleware for IoT-based smart cities: design and implementation. Sensors 14.12 (2014).

[42] GANDHI, Baratam M. Kumar; RAO, M. Kameswara. A prototype for IoT based car parking management system for smart cities. Indian Journal of Science and Technology 9.17 (2016).

[43] BANDEIRA, Thayanne Barros et al. Protótipo de estacionamento automatizado utilizando modelo computacional matricial e microcontrolador Arduino. Blucher Mathematical Proceedings, v. 1, n. 1, p. 817824, 2015.

[44] PHAM, Thanh Nam et al. A cloud-based smartparking system based on Internet-of-Things technologies. IEEE Access, v. 3, p. 1581-1591, 2015.

[45] NI, Houbo. Smart coffee maker. 2017. Disponível em:
portal.org/smash/get/diva2:1110927/FULLTEXT01.p http://www.divadf. Acesso em: 20 de ago. 2017.

[46] HOU, Jun-gang; CAO, Guang-zhong; XU, Gang. Design of temperature control system of smart coffee maker based on PIC16F877A [J]. Machine Development 10, 2005.

[47] ILLY, Andrea; MASTROPASQUA, Luca. Espresso coffee machine. U.S. Patent No. 6,109,168. 29 Aug. 2000 .

[48] ILLY, Francesco; HELL, Matthias. Coffee machine U.S. Patent No. 5,992,298. 30 Nov. 1999.

[49] SANTO, Vinícius do Espírito. Controlador de temperatura para máquina de café expresso com Arduino. (2015). Disponível em: http://repositorio.uniceub.br/handle/235/7576. Acesso em: 21 de ago. 2017

[50] PAIMAN, Sofia Murni. Arduino Coffee Pot Via Twitter. Disponível em: http://eprints.utem.edu.my/13870. Acesso em: 21 de ago. 2017.

[51] J. Errobidart, A. J. Uriz, E. Gonzalez, I. E. Gelosi and J. A. Etcheverry, "Offline domotic system using voice comands," 2017 Eight Argentine Symposium and Conference on Embedded Systems (CASE), Buenos Aires, 2017, pp. 1-6.

[52] J. C. Montesdeoca Contreras, R. S. Avila Campoverde, J. C. Cabrera Hidalgo and P. E. Vintimilla Tapia, "Mobile applications using TCP/IPGSM protocols applied to domotic," 2015 XVI Workshop on Information Processing and Control (RPIC), Cordoba, 2015, pp. 1-4

[53] Juan Pablo Cofre ; Gabriel Moraga ; Cristian Rusu; Ivan Mercado; Rodolfo Inostroza; Cristhy Jimenez. Developing a Touchscreen-based Domotic Tool for Users with Motor Disabilities. Information 
Technology: New Generations (ITNG), 2012 Ninth International Conference. 01 June 2012.

[54] L. Dobrescu, "Domotic embedded system," Proceedings of the 2014 6th International Conference on Electronics, Computers and Artificial Intelligence (ECAI), Bucharest, 2014, pp. 55-58.

[55] Eurico Leite; Luis Várela; V. Fernão Pires; Filipe D. Cardoso; A. J. Pires; João F. Martins. A ZigBee wireless domotic system with Bluetooth interface. Industrial Electronics Society, IECON 2014 - 40th Annual Conference of the IEEE. 26 February 2015.

[56] R. Alesii ; F. Graziosi ; S. Marchesani ; C. Rinaldi; M. Santic; F. Tarquini. Short range wireless solutions enabling ambient assisted living to support people affected by the Down syndrome. EUROCON, 2013 IEEE. 10 October 2013.

\section{Acknowledgments}

We would like to thank Telefonica/Vivo for the financial resources provided to the projects of the IoT laboratory, Centro Universitário FEI for the Scientific Initiation grants awarded through the PIBIC program for the students Adriano dos Santos Viana, Celso Junji Sonehara, Gabriel Pereira da Costa Andrade and Gustavo Souza Azevedo. We also thank Byanca Andreatto Maria, Victor Augusto dos Santos, Augusto Einsfeldt, Ronaldo Gonçalves dos Santos and all the people who have contributed directly or indirectly to the accomplishment of this work. 